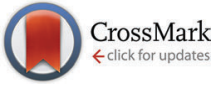

Cite this: Chem. Commun., 2015, 51, 1897

Received 10th September 2014, Accepted 11th December 2014

DOI: $10.1039 / c 4 c c 07154 a$

www.rsc.org/chemcomm

\section{Selective rearrangement of terminal epoxides into methylketones catalysed by a nucleophilic rhodium-NHC-pincer complex $\dagger$}

\author{
Eva Jürgens, ${ }^{a}$ Barbara Wucher, ${ }^{a}$ Frank Rominger, ${ }^{b}$ Karl W. Törnroos ${ }^{c}$ and \\ Doris Kunz*a
}

\begin{abstract}
An efficient $\mathrm{Rh}^{\prime}-\mathrm{NHC}$-pincer catalyst for the highly regioselective Meinwald rearrangement of monoalkylated epoxides into methylketones under mild conditions is presented. The nucleophilic epoxide opening is assisted by Lewis acids.
\end{abstract}

Epoxides are widely used as substrates in organic synthesis, ${ }^{1}$ as they can be transformed under ring opening into various functional groups. One well-documented reaction is the so-called Meinwald rearrangement, i.e. the rearrangement into aldehydes or ketones usually catalysed by Lewis acids. ${ }^{2}$ Selectivity is determined by formation of the most stable carbenium intermediate followed by an alkyl or hydride shift. ${ }^{3}$ Therefore, aldehydes are the major product when using terminal epoxides. A number of Lewis acid catalysts ${ }^{1}$ are known for internal epoxides ${ }^{3,4}$ while catalysts for the rearrangement of monoalkyl-substituted terminal epoxides are less common. Only a few catalysts are known to selectively convert monoalkylated epoxides into methylketones, e.g. $\mathrm{Pd}(\mathrm{OAc})_{2},{ }^{5, b} \mathrm{MnI}_{2}$ or $\mathrm{Co}_{2}(\mathrm{CO})_{8}$ (ref. $5 c$ ) In those cases a nucleophilic ring opening can explain the inverse product selectivity. In the following, we describe the first rhodium catalysed Meinwald rearrangement of terminal epoxides to methylketones (Scheme 1).

In 2006 we reported the highly nucleophilic character of rhodium-pincer-complex $\mathbf{1}^{6}$ that is caused by the two electrondonating N-heterocyclic carbene moieties (Fig. 1). ${ }^{7}$ Therefore, complex 1 seems to be a promising candidate for catalysing the nucleophilic epoxide rearrangement. Initially, we carried out the reaction with various epoxides in the presence of

\footnotetext{
${ }^{a}$ Institut für Anorganische Chemie, Eberhard Karls Universität Tübingen,

Auf der Morgenstelle 18, 72076 Tübingen, Germany.

E-mail: Doris.Kunz@uni-tuebingen.de

${ }^{b}$ Institut für Organische Chemie, Heidelberg University, Im Neuenheimer Feld 250, 69120 Heidelberg, Germany

${ }^{c}$ Department of Chemistry, University of Bergen, Allégaten 41, 5007 Bergen, Norway $\dagger$ Electronic supplementary information (ESI) available: Experimental procedures, NMR spectra and crystallographic data. CCDC 1018408 (4a) and 1018409 (4b). For ESI and crystallographic data in CIF or other electronic format see DOI: $10.1039 / \mathrm{c} 4 \mathrm{cc} 07154 \mathrm{a}$
}

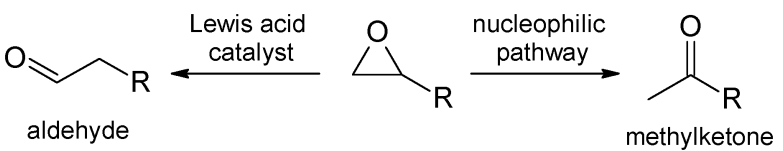

Scheme 1 Rearrangement of terminal epoxides (Meinwald reaction).

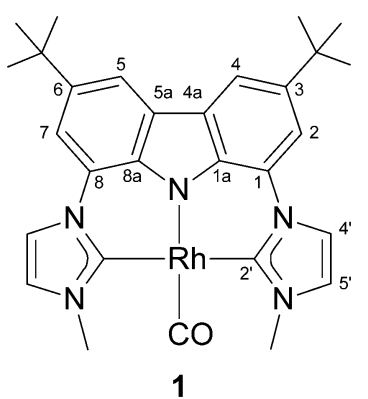

Fig. 1 The highly nucleophilic NHC-pincer rhodium complex 1.

$10 \mathrm{~mol} \%$ of pure complex 1 , but no reaction could be achieved. However, upon addition of a stoichiometric amount of lithium chloride in tetrahydrofuran a rearrangement product was detected in low yields.

Using dichloromethane or acetonitrile suppresses the rearrangement to the methylketone and results in formation of new organometallic species (vide infra), ${ }^{8}$ while benzene improved the reaction rate remarkably. In addition, lithium salts of weakly coordinating anions such as lithium tetrakis(pentafluorophenyl)borate or lithium bis(trifluoromethanesulfonimide) $\left(\mathrm{LiNTf}_{2}\right.$ ) led to very high reaction rates at $60{ }^{\circ} \mathrm{C}$ (see $\mathrm{ESI} \dagger$ for optimisation details).

As strong Lewis acids can act as catalysts for the epoxide rearrangements themselves, we checked their individual reactivity towards 1,2-epoxyhexane, but none of the Lewis acid additives used catalyses the rearrangement on its own, not even at elevated temperatures of up to $120^{\circ} \mathrm{C}$ in thf and $80{ }^{\circ} \mathrm{C}$ in benzene. We then optimised the amount of catalyst, lithium salt additive as well as the reaction temperature by analysing 
Table 1 Optimisation of the reaction conditions: influence of catalyst loading and temperature on the reaction ${ }^{a}$

\begin{tabular}{llllll}
\hline Entry & $T\left[{ }^{\circ} \mathrm{C}\right]$ & $\mathbf{1}[\mathrm{mol} \%]$ & LiNTf $_{2}[\mathrm{~mol} \%]$ & Time $[\mathrm{min}]$ & Yield $^{b, c}[\%]$ \\
\hline 1 & 25 & 10 & 10 & 100 & 3 \\
2 & 40 & 10 & 30 & 100 & 7 \\
3 & 60 & 10 & 10 & 100 & 51 \\
4 & 60 & 10 & 30 & 100 & 94 \\
5 & 60 & 10 & 50 & 100 & 98 \\
6 & 80 & 10 & 10 & 100 & 98 \\
7 & 60 & 1 & 30 & 120 & 18 \\
8 & 60 & 5 & 20 & 120 & 95
\end{tabular}

${ }^{a}$ Reaction conditions: 1 (10 mol\%), 1,2-epoxyhexane $(35 \mu \mathrm{L}) .0 .5 \mathrm{~mL}$ benzene, $100 \mathrm{~min}$, all reactions were carried out using a J. Young NMR tube. ${ }^{b}$ The ketone was the only observed reaction product. ${ }^{c}$ Yield was determined by ${ }^{1} \mathrm{H}$ NMR using 1,3,5-trimethoxybenzene as internal standard.

the reaction mixture after $100 \mathrm{~min}$ (Table 1). The rearrangement proceeded almost quantitatively after this time when using $30-$ $50 \mathrm{~mol} \%$ of $\mathrm{LiNTf}_{2}$ and $10 \mathrm{~mol} \%$ of $1(\mathrm{Rh}: \mathrm{Li}=1: 3-1: 5)$ at $60^{\circ} \mathrm{C}$ (entries 3-5) or only $10 \mathrm{~mol} \%$ of the Li additive at $80^{\circ} \mathrm{C}$ (entry 6), but already at room temperature or $40{ }^{\circ} \mathrm{C}$ slow rearrangement is observed (entries 1 and 2). Reducing the catalyst loading to $1 \mathrm{~mol} \%$ decreases the reaction rate affording only $18 \%$ of the methylketone after $2 \mathrm{~h}$ (entry 7). Good results are still achieved using $5 \mathrm{~mol} \%$ of 1 and $20 \mathrm{~mol} \% \operatorname{LiNTf}_{2}$ at $60{ }^{\circ} \mathrm{C}(95 \%$ yield after $2 \mathrm{~h}$; entry 8). All experiments with 1,2-epoxyhexane gave the methylketone as the sole rearrangement product; the respective aldehyde was never detected.

The best results for this reaction have been reported by Kagan as well as Kulawiec with a combination of $\operatorname{Pd}(\mathrm{OAc})_{2}$ and $\mathrm{PBu}_{3}$ that resulted in the selective formation of the ketone at $120{ }^{\circ} \mathrm{C}$ in toluene without the use of any additive. ${ }^{5 a, b}$ Using $\mathrm{SmI}_{2}, \mathrm{MnI}_{2}$ or $\mathrm{Co}_{2}(\mathrm{CO})_{8}$ also formed the corresponding ketones with a selectivity of above $95 \%$ and reaction times between $2 \mathrm{~h}$ $\left(\mathrm{MnI}_{2}, 70{ }^{\circ} \mathrm{C}\right)$ and $24 \mathrm{~h}\left(\mathrm{Co}_{2}(\mathrm{CO})_{8}, 40{ }^{\circ} \mathrm{C}, \mathrm{MeOH}\right)$, but only yields between $70-80 \%$ were obtained. ${ }^{5 c}$ To probe the nucleophilic effect of our rhodium catalyst, we then tested commercially available Wilkinson catalyst $\left[\mathrm{Rh}\left(\mathrm{PPh}_{3}\right)_{3} \mathrm{Cl}\right]$ and $[\mathrm{Rh}(\mu-\mathrm{Cl})(\mathrm{COD})]_{2}$ under our optimized conditions $\left(100 \mathrm{~min}, 60{ }^{\circ} \mathrm{C}\right.$, benzene, $30 \mathrm{~mol} \%$ LiNTf $_{2}$ ) with 1,2-epoxyhexane, but observed only inferior results (Table 2). About 35\% of the methylketone could be obtained when heating the reaction mixture with $\left[\mathrm{Rh}\left(\mathrm{PPh}_{3}\right)_{3} \mathrm{Cl}\right]$ at $85{ }^{\circ} \mathrm{C}$ for $60 \mathrm{~h}$. In the case of $[\mathrm{Rh}(\mu-\mathrm{Cl})(\mathrm{COD})]_{2}$ no catalytic activity was observed applying these conditions.

As a first substrate scope, we found that propylenoxide is rearranged to acetone in excellent yields (Table 3, entry 1), whereas styrene oxide gave a mixture of acetophenone and 2-phenylacetaldehyde at $60{ }^{\circ} \mathrm{C}$ in a $3: 2$ ratio in an only overall $10 \%$ yield after $2 \mathrm{~h}$ (entry 3 ). A blank test revealed that LiNTf $_{2}$ itself reacts with styrene oxide leading exclusively to the aldehyde at $60{ }^{\circ} \mathrm{C}$. This side reaction can be suppressed completely when lowering the temperature to $30{ }^{\circ} \mathrm{C}$, however, only $5 \%$ of acetophenone were obtained after $16 \mathrm{~h}$ (entry 4$)$. Using $\mathrm{LiCl}$ as a
Table 2 Comparison of catalyst 1 with other rhodium complexes and literature examples of other metal catalysts

\begin{tabular}{|c|c|c|c|c|c|c|}
\hline & $\overbrace{\mathrm{R}}^{\mathrm{O}}$ & $\begin{array}{c}5 \mathrm{~mol} \% 1 \\
20 \mathrm{~mol} \% \mathrm{LiN} \\
60{ }^{\circ} \mathrm{C}, \mathrm{C}_{6} \mathrm{D}_{6} \\
\end{array}$ & & & r & \\
\hline Entry & Catalyst & & $\begin{array}{l}\text { Amount } \\
{[\mathrm{mol} \%]}\end{array}$ & $\begin{array}{l}\text { Temp. } \\
{\left[{ }^{\circ} \mathrm{C}\right]}\end{array}$ & $\begin{array}{l}\text { Time } \\
{[\mathrm{h}]}\end{array}$ & $\begin{array}{l}\text { Yield } \\
\text { [\%] }\end{array}$ \\
\hline 1 & 1 & & 10 & 60 & 2 & $98^{a, b, c}$ \\
\hline 2 & $\mathrm{Rh}\left(\mathrm{PPh}_{3}\right)_{3} \mathrm{Cl}$ & & 10 & 60 & 2 & $0^{a, b, c}$ \\
\hline 3 & $\mathrm{Rh}\left(\mathrm{PPh}_{3}\right)_{3} \mathrm{Cl}$ & & 10 & 85 & 60 & $35^{a, b, c}$ \\
\hline 4 & {$[\mathrm{Rh}(\mu-\mathrm{Cl})(\mathrm{COD})]_{2}$} & & 10 & 60 & 2 & $0^{a, b, c}$ \\
\hline 5 & {$[\mathrm{Rh}(\mu-\mathrm{Cl})(\mathrm{COD})]_{2}$} & & 10 & 85 & 60 & $0^{a, b, c}$ \\
\hline $6^{5 c}$ & $\mathrm{Co}_{2}(\mathrm{CO})_{8}($ ref. $5 \mathrm{c})$ & & 4 & 40 & 24 & 71 \\
\hline $7^{5 a, b}$ & $\mathrm{Pd}(\mathrm{OAc})_{2}, \mathrm{PBu}_{3}(\mathrm{r}$ & f. $5 a$ and $b$ ) & $5-10$ & 120 & 3 & 88 \\
\hline
\end{tabular}

${ }^{a}$ Reaction conditions: $\operatorname{LiNTf}_{2}(30 \mathrm{~mol} \%), 60{ }^{\circ} \mathrm{C}, \mathrm{C}_{6} \mathrm{D}_{6}(0.5 \mathrm{~mL})$, all reactions were carried out in a $J$. Young NMR tube with 1,2-epoxyhexane $(35 \mu \mathrm{L})$ as substrate. ${ }^{b}$ The ketone was observed as sole reaction product. ${ }^{c}$ Yield was determined by ${ }^{1} \mathrm{H}$ NMR using 1,3,5-trimethoxybenzene as internal standard.

Table 3 Rhodium catalyzed Meinwald rearrangement of epoxides into methylketones

\begin{tabular}{|c|c|c|c|c|}
\hline Entry & Substrate & Product & $\begin{array}{l}\text { Time } \\
{[\mathrm{h}]}\end{array}$ & $\begin{array}{l}\text { Yield }^{a, b} \\
{[\%]}\end{array}$ \\
\hline 1 & & Acetone & 3 & 93 \\
\hline 2 & & 2-Hexanone & 2 & 95 \\
\hline 3 & & $\begin{array}{l}\text { Acetophenone: } \\
\text { 2-phenylacetaldehyde }\end{array}$ & 2 & $6: 4$ \\
\hline 4 & & Acetophenone & 16 & $5^{c}$ \\
\hline 5 & & Cyclohexanone & 24 & $80^{d}$ \\
\hline 6 & & No ketone traces of aldehyde & 24 & 0 \\
\hline
\end{tabular}

${ }^{a}$ Reaction conditions: 1 (5 mol\%), LiNTf 2 (20 mol\%), $60{ }^{\circ} \mathrm{C}$, all reactions were carried out in a J. Young NMR tube in $\mathrm{C}_{6} \mathrm{D}_{6}(0.4 \mathrm{~mL})$. ${ }^{b}$ Yield was determined by ${ }^{1} \mathrm{H}$ NMR using 1,3,5-trimethoxybenzene as internal standard. ${ }^{c}$ At $30{ }^{\circ} \mathrm{C} .{ }^{d}$ At $80{ }^{\circ} \mathrm{C}$.

Lewis acid additive $\left(60{ }^{\circ} \mathrm{C}\right)$ did not lead to any rearrangement product. Cyclohexene oxide, a 1,2-disubstituted epoxide, can be rearranged to cyclohexenone in $80 \%$ yield $\left(80{ }^{\circ} \mathrm{C}\right.$, entry 5$)$. As expected 2,2-dimethyloxirane did not rearrange into a ketone as the reaction is blocked by the additional methyl substituent (entry 6). Traces of the aldehyde were formed due to Lewisacidic epoxide opening by $\operatorname{LiNTf}_{2}$ (blank test).

A nucleophilic mechanism for the Meinwald reaction was suggested for $\mathrm{Co}_{2}(\mathrm{CO})_{8}$ in methanol that involves in situ formation of the nucleophile $\left[\mathrm{Co}(\mathrm{CO})_{4}\right]^{-}$as well as cationic $\left[\mathrm{Co}(\mathrm{MeOH})_{6}\right]^{+}$to activate the epoxide upon coordination. ${ }^{5-e}$ Therefore, a plausible mechanism for our $16 \mathrm{e}^{-}$rhodium 


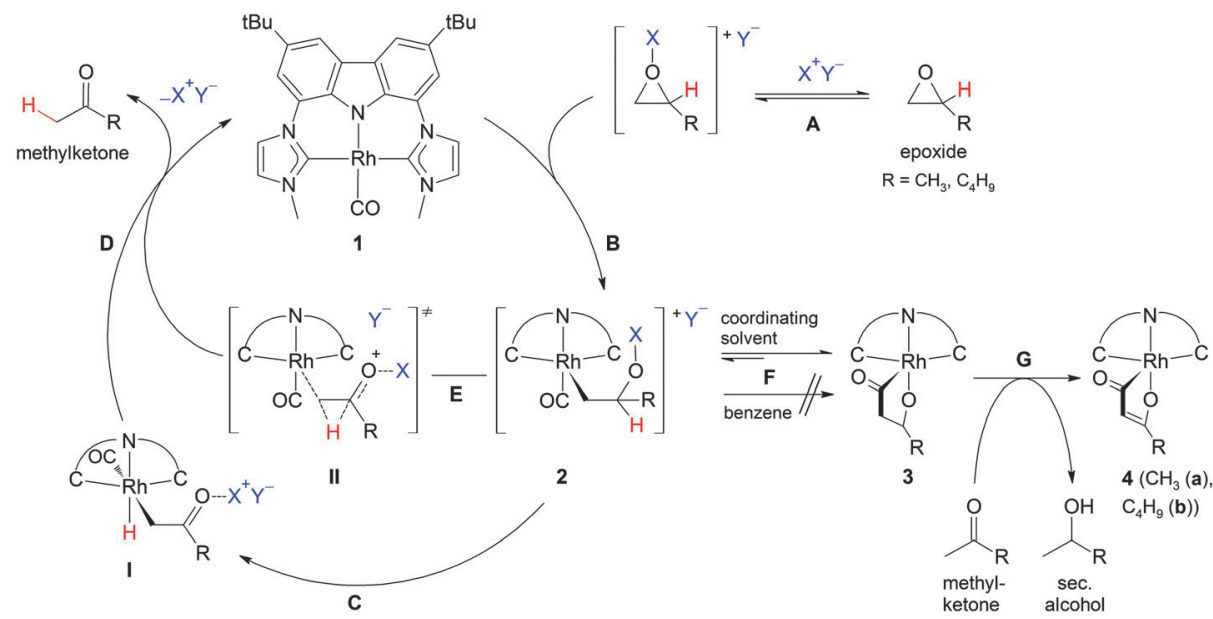

Scheme 2 Proposed reaction pathway for the conversion of monoalkyl-substituted epoxides to methylketones catalyzed by 1.

complex 1 starts with preactivation of the epoxide by the Lewis acid additive (Scheme 2, (A)) followed by a nucleophilic attack of the $\mathrm{Rh}^{\mathrm{I}}$ centre at the most electrophilic side of the epoxide which is also the least hindered one. In $\mathrm{C}_{6} \mathrm{D}_{6} \mathrm{Rh}^{\mathrm{III}}$ intermediate 2 (B) is obtained which was confirmed by in situ formation of 2 in a stoichiometric reaction at RT. The metal bound CO ligand was identified by its ${ }^{13} \mathrm{C}$ NMR chemical shift of $\delta=207 \mathrm{ppm}$ and an IR stretching frequency (benzene) at $2046 \mathrm{~cm}^{-1}$. ${ }^{9}$ Subsequent $\beta$-hydride migration (C) could lead to the $\mathrm{Rh}^{\mathrm{III}}$ hydrido complex I that releases the ketone by reductive elimination (D) under regeneration of $\mathrm{Rh}^{\mathrm{I}}$ complex $\mathbf{1}$. So far, no metal hydrido complex was observed during reaction, which could be due to a fast reductive elimination process. Alternatively, intermediate 2 could release the product directly by a concerted 1,2-hydride shift- $\mathrm{S}_{\mathrm{N}} \mathrm{i}$ reaction via transition state II (E) to release the product and close the catalytic cycle.

In thf- $\mathrm{d}_{8}$ however, only formation of $\mathbf{3}$ upon $\mathrm{CO}$ insertion (F) was observed during the NMR spectroscopic monitoring of the catalytic reaction. ${ }^{9}$ The identical product 3 could be synthesized independently by a stoichiometric reaction of 1 with one equivalent of the respective epoxide in the presence of the Lewis acid additive in tetrahydrofuran (room temperature) or acetonitrile $\left(60{ }^{\circ} \mathrm{C}\right)$. The ${ }^{1} \mathrm{H}$ NMR spectrum of 3 in thf- $\mathrm{d}_{8}$ solution displays a double set of resonances for the ligand backbone due to the reduced symmetry of the complex $\left(\mathrm{R}=\mathrm{CH}_{3}\right)$. A doublet at $1.16 \mathrm{ppm}$ is assigned to the methyl group resulting from the reaction of the epoxide with rhodium complex 1. The other characteristic peaks of the ring-opened epoxide moiety are superimposed by the residual solvent peak (thf- $\mathrm{d}_{8}$ ) and epoxide signals, but could be detected by 2D NMR experiments as well as in acetonitrile- $\mathrm{d}_{3}$. In the ${ }^{13} \mathrm{C}$ NMR spectrum (thf- $\left.\mathrm{d}_{8}\right)$ the doublet at $229.4 \mathrm{ppm}\left({ }^{1} J_{\mathrm{RhC}}=43.3 \mathrm{~Hz}\right)$ strongly hints towards a $\mathrm{CO}$ insertion and formation of the $\mathrm{Rh}$ acyl complex 3. In addition a ${ }^{13} \mathrm{C}$ DEPT- 135 experiment confirms the signal for the $\mathrm{CH}_{2}$ group at $26.1 \mathrm{ppm}\left({ }^{2} J_{\mathrm{RhC}}=30.0 \mathrm{~Hz}\right)$. Proof that compound 3 is a resting state and can react (partly) back into the catalytic cycle was obtained by removing all volatiles in vacuo after generation of 3 and redissolving the residue in

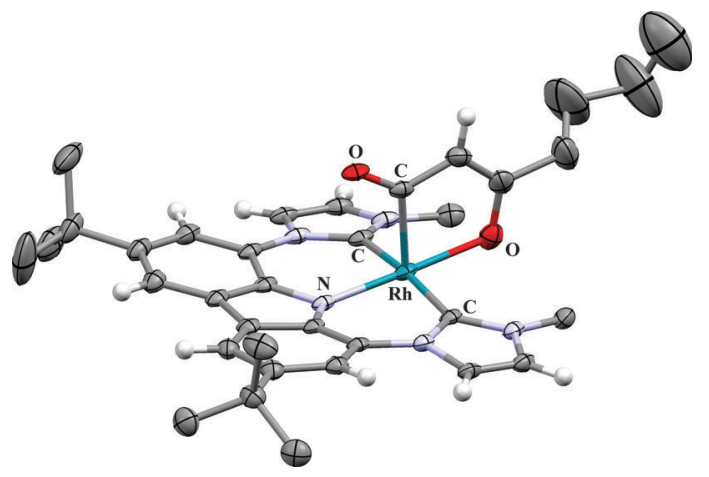

Fig. 2 X-ray crystal structure of the side product $\mathbf{4 b}$ bearing an unsaturated rhodacycle. For reason of better clarity, the anisotropic displacement parameters are given at the $20 \%$ probability level and only the hydrogen atoms of $\mathrm{sp}^{2}$-hybridized C-atoms are shown and solvent molecules omitted. ${ }^{9}$

thf- $\mathrm{d}_{8}$. After $2 \mathrm{~d}$ at room temperature the peaks of 3 cannot be detected, whilst the peak of acetone as well as the signals of isopropanol and the poorly soluble yellow species $4 a$ appear.

The ${ }^{13} \mathrm{C}$ DEPT-135 experiment of this species reveals the signal of a $\mathrm{CH}$ group at $93.6 \mathrm{ppm}$; the respective proton signal is found at $\delta_{\mathrm{H}}=3.96 \mathrm{ppm}$. All other peaks also coincide well with the formation of complex $4 \mathbf{a}$ by dehydrogenation (G). Single crystals suitable for X-ray diffraction were obtained from saturated solutions of the reaction mixtures at room temperature. The analyses confirm formation of the unsaturated five-membered rhodacycles in complexes 4a and $\mathbf{b}$ (Fig. 2, for $4 \mathbf{a}$ see ESI $\dagger$ ). This also explains the formation of isopropanol from acetone during the course of the reaction. Formation of $\mathbf{4}$ can only be observed after formation of complex 3. In pure $\mathrm{C}_{6} \mathrm{D}_{6}$ neither complex 3 nor complex 4 is obtained. However, after generation of $3\left(\mathrm{R}=\mathrm{CH}_{3}\right)$ in thf- $\mathrm{d}_{8}$, removal of all volatiles in vacuo and dissolving of the residue in $\mathrm{C}_{6} \mathrm{D}_{6}$, the formation of both, complex $\mathbf{1}$ and acetone as well as formation of complex $\mathbf{4 a}$ is observed. We assume that residual thf- $\mathrm{d}_{8}$, coordinated to the $\mathrm{Li}^{+}$ cation, prevents direct observation of 2 under these conditions.

We showed that terminal epoxides can be transformed into ketones under mild conditions using the strong nucleophilic 
rhodium catalyst 1 . To the best of our knowledge this is the most reactive and selective catalyst for this transformation and the first example of a rhodium catalyst yielding the methylketone as product.

Financial support from the Deutsche Forschungsgemeinschaft (SFB 623, GK 850) as well as the BMBF and MWK-BW (Professorinnenprogramm, LGF for E.J.) is gratefully acknowledged. We thank Lars Wesemann for a helpful discussion.

\section{Notes and references}

1 J. G. Smith, Synthesis, 1984, 629.

2 (a) J. Meinwald, S. S. Labana and M. S. Chadha, J. Am. Chem. Soc., 1963, 85, 582; (b) B. Rickborn, in Comprehensive Organic Synthesis, ed. B. M. Trost, Pergamon, Oxford, 1991, vol. 3, pp. 733-775.

3 (a) B. Rickborn and R. M. Gerkin, J. Am. Chem. Soc., 1971, 93, 1693; (b) D. Milstein, O. Buchman and J. Blum, J. Org. Chem., 1977, 42, 2299; (c) S. Kulasegaram and R. J. Kulawiec, J. Org. Chem., 1997, 62, 6547; (d) B. C. Ranu and U. Jana, J. Org. Chem., 1998, 63, 8212; (e) A. M. Anderson, J. M. Blazek, P. Garg, B. J. Payne and R. S. Mohan, Tetrahedron Lett., 2000, 41, 1527; $(f)$ M. Robinson, K. Pillinger and A. Graham, Tetrahedron Lett., 2006, 33, 5919; $(g)$ D. J. Vyas, E. Larionov, C. Besnard, L. Guénée and C. Mazet, J. Am. Chem. Soc., 2013, 135, 6177; (h) N. Humbert, D. J. Vyas, C. Besnard and C. Mazet, Chem. Commun., 2014, 50, 10592.
4 (a) K. Suda, K. Baba, S. Nakajima and T. Takanami, Tetrahedron Lett., 1999, 40, 7243; (b) A. Procopio, R. Dalpozzo, A. De Nino, M. Nardi, G. Sindona and A. Tagarelli, Synlett, 2004, 2633; (c) H. O. J. House, J. Am. Chem. Soc., 1955, 77, 3070; (d) Y. Kita, S. Kitagaki, Y. Yoshida, S. Mihara, D. F. Fang, M. Kondo, S. Okamoto, R. Imai, S. Akai and H. J. Fujioka, J. Org. Chem., 1997, 62, 4991.

5 (a) S. Kulasegaram and R. J. Kulawiec, Tetrahedron, 1998, 54, 1361; (b) S. Kulasegaram and R. J. Kulawiec, J. Org. Chem., 1994, 59, 7195; (c) J. Prandi, J. L. Namy, G. Menoret and H. B. Kagan, J. Organomet. Chem., 1985, 285, 449; (d) J. L. Eisenmann, R. Yamartino and J. Howard Jr., J. Org. Chem., 1961, 26, 2102; (e) J. L. Eisenmann, J. Org. Chem., 1962, 27, 2706.

6 (a) M. Moser, B. Wucher, F. Rominger and D. Kunz, Organometallics, 2007, 26, 1024; (b) B. Wucher, M. Moser, S. A. Schumacher, F. Rominger and D. Kunz, Angew. Chem., 2009, 121, 4481 (Angew. Chem., Int. Ed., 2009, 48, 4417).

7 (a) D. Bourissou, O. Guerret, F. P. Gabbaï and G. Bertrand, Chem. Rev., 2000, 100, 39; (b) W. A. Herrmann, Angew. Chem., 2002, 114, 1342 (Angew. Chem., Int. Ed., 2002, 41, 1290); (c) F. E. Hahn and M. C. Jahnke, Angew. Chem., 2008, 120, 3166 (Angew. Chem., Int. Ed., 2008, 47, 3122); (d) S. Diez-Gonzalez, N. Marion and S. P. Nolan, Chem. Rev., 2009, 109, 3612; (e) D. Kunz and E. Jürgens, in Molecular Catalysts: Structure and Functional Design, ed. L. H. Gade and P. Hofmann, Wiley-VCH, Weinheim, 2014, pp. 183-206.

8 In dichloromethane oxidative addition (trans) of the solvent to complex 1 is observed which leads to [ $\mathrm{Rh}($ bimca $\left.) \mathrm{Cl}\left(\mathrm{CH}_{2} \mathrm{Cl}\right)(\mathrm{CO})\right]$. M. Moser, PhD thesis, Heidelberg University, Heidelberg, 2007.

9 See the ESI $\dagger$ for details. 